\title{
Carcinogenicity of polychlorinated biphenyls and polybrominated biphenyls
}

In February 2013, 26 experts from 12 countries met at the International Agency for Research on Cancer (IARC), Lyon, France, to reassess the carcinogenicity of polychlorinated biphenyls (PCBs) and polybrominated biphenyls (PBBs). These assessments will be published as volume 107 of the IARC Monographs. ${ }^{1}$

PCBs are a class of aromatic compounds comprising 209 congeners, each containing one to ten chlorine atoms attached to a biphenyl nucleus. Technical PCB products, which were manufactured to obtain a specific level of chlorination, are mixtures of many PCB congeners. These products were widely used as dielectric fluid in capacitors and transformers, and to a lesser extent in building materials (eg, caulking, paints, and lighting ballasts). PCB production and new use were banned in most countries by the 1980 s, but production has been reported recently in North Korea.

Earlier, occupational exposure was highest during manufacture of PCBs, transformers, and capacitors; today, exposure can come from demolition, dysfunction, or uncontrolled recycling of PCB-contaminated structures and equipment. $P C B$ s are persistent and bioaccumulate; they have become ubiquitous environmental pollutants, including in polar regions and the deep ocean. Because of weathering and biotransformation, the $\mathrm{PCB}$ profiles noted in the environment or during biomonitoring differ from those of the commercial products. The general population is exposed mainly via food, mostly from contaminated animal fats; two major episodes of food poisoning took place in Japan and Taiwan, China, where cooking oil was accidentally contaminated with PCBs. Indoor air can also contribute to human exposure. Worldwide monitoring programmes have shown that PCBs are present in most samples of human milk.
PCB congeners can be categorised by their degree of chlorination, substitution pattern, and binding affinity to receptors. 12 congeners with a strong affinity for the aryl hydrocarbon receptor (AhR) are referred to as dioxinlike PCBs. PCBs are readily absorbed and distributed in the body, and accumulate in adipose tissue. Biotransformation of all PCB congeners starts with cytochrome P450-dependent monooxygenation. Low-chlorinated PCBs are readily metabolised into highly reactive electrophilic species (ie, arene oxides, quinones) which, in addition to producing DNA adducts and reactive oxygen species, are directly genotoxic and mutagenic. ${ }^{2}$ By contrast, highly chlorinated $\mathrm{PCBs}$ are poorly metabolised but, through induction of xenobiotic-metabolising enzymes, can also generate reactive oxygen species, lipid peroxidation, oxidative and alkylating DNA adducts, and can eventually cause genotoxic effects.

Individual PCBs activate numerous receptors, including $A h R$ and the constitutive androstane and pregnane xenobiotic receptors (CAR/PXR). AhR activation is one of the key events linked to carcinogenesis mediated by dioxin-like PCBs. Sustained activation leads to deregulation of cell-cycle control and cell proliferation, inhibition of apoptosis, suppression of cell-to-cell communication and adhesion, and increased cell plasticity and invasiveness. Non-dioxin-like PCBs induce many of these effects via several AhR-independent mechanisms, including activation of the constitutive androstane and pregnane xenobiotic receptors, and perturbations in cell-tocell communication and cell adhesion.

PCBs can compromise the immune surveillance mechanism. Highly chlorinated PCBs with a strong affinity for the AhR are potent immunotoxicants; less-chlorinated PCBs, which are less immunotoxic, act via AhR-independent mechanisms, including metabolic activation. Both low-chlorinated and high-chlorinated PCBs are associated with chronic inflammatory responses. Non-dioxinlike PCBs can stimulate the production of inflammatory mediators, whereas dioxin-like PCBs can inhibit such reaction. By contrast, some dioxin-like PCBs, but not non-dioxin-like PCBs, can compromise the normal function of the vascular endothelium.

PCBs target the endocrine system. Several models have shown direct modulation of nuclear steroid hormone-dependent gene expression by PCBs. Furthermore, depending on their structure, monohydroxylated PCB metabolites can act as oestrogen agonists or antagonists. These disruptions might have reproductive, toxic, and carcinogenic consequences.

The Working Group considered more than 70 independent epidemiological studies with informative data for carcinogenicity of $\mathrm{PCBs}$ in human beings. Excess risks for melanoma were reported in several studies, mainly cohort studies of workers in the manufacture of capacitors and transformers, and in electric power and equipment maintenance. A significant linear exposure-response trend was noted in the largest study. ${ }^{3}$ In a populationbased case-control study that assessed exposure with PCB serum levels, the association persisted after control for sun sensitivity and exposure. ${ }^{4}$ The association of melanoma and PCBs was noted consistently in occupational studies in different industries in North America and Europe, in studies of the general population, and with cohort and case-control designs. Thus, the Working Group concluded that there is sufficient evidence in humans for the carcinogenicity of PCBs. Notably, AhR can modulate melanogenesis, ${ }^{5}$ which lends mechanistic plausibility to this

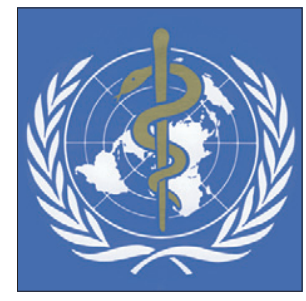

Published Online March 15, 2013 http://dx.doi.org/10.1016/ S1470-2045(13)70104-9

For more on the IARC

Monographs see

http://monographs.iarc.fr/

Upcoming meetings June 4-11, 2013 Volume 108: Some drugs and herbal medicines

Oct 8-15, 2013

Volume 109: Ambient air pollution

Monograph Working Group Members

VJ Cogliano (USA)-Chair K Aronson, HTryphonas (Canada); Y L Guo (Taiwan, China); M Machala (Czech Republic);

EC Bonefeld-Jørgensen, K Vorkamp (Denmark) J P Cravedi, B Le Bizec, J F Narbonne (France); H Esch (Germany); P Cocco,

F Merletti (Italy); R Vermeulen (unable to attend; Netherlands); A Agudo (Spain); $\mathrm{N}$ Johansson (Sweden); H Fiedler, N Hopf (Switzerland); H P Glauert, R A Herbert, M O James, G Ludewig, L Robertson, A Ruder, N Walker (USA)

Invited Specialists D O Carpenter (USA)

Representatives

R Johnson (National Cancer Institute, USA); B Stewart (Cancer Australia, Australia) Observers

E A Carlson (General Electric Company, USA); N Falette (Léon Bérard Centre, France); J D Schell (Solutia Inc and Monsanto Company, both USA)

IARC Secretariat

R Baan, L Benbrahim-Tallaa, V Bouvard, R Carel, F El Ghissassi, Y Grosse, N Guha, B Lauby-Secretan, D Loomis, H Mattock, S Rinaldi, A Scalbert, LSchinasi, K Straif 
Conflicts of interest

VJC is an employee of the US Environmental Protection Agency, and directs their IRIS programme, which develops health assessments of chemicals found in the environment. EC is employed by the General Electric Company and works on PCB liability issues. As a General Electric employee, he owns stock in the company. JS attended on behalf of Monsanto Company and Solutia Inc. All other Working Group members, specialists, representatives, and IARC secretariat declare that they have no conflicts of interest. association. Increased risks for nonHodgkin lymphoma and breast cancer were also reported, both of which are biologically plausible. However, the associations were not consistent and were considered as providing limited evidence. Data for cancers at other sites were too sparse to draw any conclusions.

The carcinogenicity of PCBs in animals has been assessed for individual congeners; binary mixtures of congeners; technical mixtures containing various congeners; and simulated environmental mixtures, with 2 year bioassays; studies with perinatal and postnatal exposure and studies that examined the initiating and promoting activities of PCBs. Individual congeners (PCB118, PCB126) and several commercial products with a high chlorine content induced benign and malignant tumours of the liver, lung, and oral mucosa in rats; these studies provided sufficient evidence of carcinogenicity in experimental animals. ${ }^{6,7}$ These congeners and mixtures include AhR agonists that exhibit dioxin-like activities, and CAR agonists. ${ }^{8}$ Other PCB congeners (PCB153) and lowchlorinated commercial products, which were less well studied than highly chlorinated products, showed limited evidence of carcinogenicity in experimental animals. ${ }^{9}$ The relative contributions of different PCB congeners to the carcinogenicity of the commercial mixtures are not known.

Overall, all PCBs can induce formation of reactive oxygen species, genotoxic effects, immune suppression, an inflammatory response, and endocrine effects to various extents and through different pathways. The dioxin-like PCBs exert their effects mainly through AhR activation and the downstream cascade of related events; less-chlorinated PCBs act more readily through metabolic activation and the downstream effects of these metabolites. Thus, mixtures might have more than additive effects.
On the basis of sufficient evidence of carcinogenicity in humans and experimental animals, the Working Group classified PCBs as carcinogenic to humans (Group 1). Additionally, dioxinlike PCBs were also classified in Group 1 on the basis of extensive evidence of an AhR-mediated mechanism of carcinogenesis that is identical to that of 2,3,7,8-tetrachlorodibenzopara-dioxin, and sufficient evidence of carcinogenicity in experimental animals. However, the carcinogenicity of PCBs cannot be solely attributed to the carcinogenicity of the dioxin-like PCBs.

PBBs resemble $\mathrm{PCBs}$, with bromine rather than chlorine atoms. PBBs were used mainly as flame retardants in the 1970s, but production has been discontinued in most countries for many years. One release of PBBs took place in Michigan, USA, where they were inadvertently distributed as cattle-feed supplement, contaminating many agricultural products. Similar to $\mathrm{PCBs}$, PBBs are highly lipophilic, bioconcentrate and bioaccumulate, and are environmental contaminants worldwide. FireMaster FF-1, the most widely used commercial PBB product, consistently induced benign and malignant hepatocellular tumours in rats and mice, and cholangiocarcinomas in rats. ${ }^{10} \mathrm{PBBs}$, like their chlorinated analogues, are ligands to several cellular and nuclear receptors, including AhR. They are efficacious inducers of hepatic drug metabolism, accelerating the biotransformation of both endogenous and exogenous compounds. PBBs have various adverse effects including suppression of the immune system and disruption of normal hormone function. They are efficient promoters in twostage rodent hepatocarcinogenesis bioassays. Although PBBs have received less attention and study, the available data indicate that PBB congeners exhibit their toxic effects and carcinogenic potential via many of the same pathways as their chlorinated counterparts. On the basis of these similarities with PCBs, and together with inadequate evidence for carcinogenicity in humans and sufficient evidence in experimental animals, PBBs were upgraded to Group 2A, probably carcinogenic to humans.

Béatrice Lauby-Secretan, Dana Loomis, Yann Grosse, Fatiha El Ghissassi, Véronique Bouvard, Lamia Benbrahim-Tallaa, Neela Guha, Robert Baan, Heidi Mattock, Kurt Straif, on behalf of the International Agency for Research on Cancer Monograph Working Group IARC, Lyon, France

We declare that we have no conflicts of interest.

1 IARC. IARC monographs on the evaluation of carcinogenic risks to humans, volume 107. Polychlorinated and polybrominated biphenyls. Lyon: International Agency for Research on Cancer (in press)

2 Ludewig G, Robertson LW. Polychlorinated biphenyls (PCBs) as initiating agents in hepatocellular carcinoma. Cancer Lett 2012; published online Dec 2. DOI:10.1016/j. canlet.2012.11.041.

3 Loomis D, Browning SR, Schenck AP, et al. Cancer mortality among electric utility workers exposed to polychlorinated biphenyls. Occup Environ Med 1997; 54: 720-28.

4 Gallagher RP, Macarthur AC, Lee TK, et al. Plasm levels of polychlorinated biphenyls and risk of cutaneous malignant melanoma: a preliminary study. Int J Cancer 2011; 128: 1872-80.

5 Luecke S, Backlund M, Jux B, et al. The aryl hydrocarbon receptor (AHR), a novel regulator of human melanogenesis. Pigment Cell Melanoma Res 2010; 23: 828-33.

6 National Toxicology Program. NTP toxicology and carcinogenesis studies of

3,3',4,4',5-pentachlorobiphenyl (PCB 126) (CAS No. 57465-28-8) in female Harlan Sprague-Dawley rats (Gavage Studies) Nat/ Toxicol Program Tech Rep Ser 2006 520: 4-246.

7 National Toxicology Program. NTP toxicology and carcinogenesis studies of 2,3',4,4',5-pentachlorobiphenyl (PCB 118) (CAS No. 31508-00-6) in female Harlan Sprague-Dawley rats (Gavage studies) Nat/ Toxicol Program Tech Rep Ser 2010 559: 1-174.

8 Silberhorn EM, Glauert HP, Robertson LW. Carcinogenicity of polyhalogenated biphenyls: PCBs and PBBs. Crit Rev Toxicol 1990; 20: 440-96.

9 National Toxicology Program. NTP technical report on the toxicology and carcinogenesis studies of 2,2',4,4',5,5'-hexachlorobiphenyl (PCB 153) (CAS No. 35065-27-1) in female Harlan Sprague-Dawley rats (Gavage studies) Natl Toxicol Program Tech Rep Ser 2006; 529: 4-168.

10 National Toxicology Program. NTP toxicology and carcinogenesis studies of polybrominated biphenyls (CAS No. 67774-32-7) (Firemaster FF-1(R)) in F344/N Rats and B6C3F1 mice (Feed Studies). Natl Toxicol Program Tech Rep Ser 1993; 398: 1-235. 